\title{
LA CONSTRUCCIÓN DE UN CONCEPTO \\ DE CIENCIA EN CHILE: \\ MANUEL DE SALAS Y CLAUDIO GAY
}

\author{
Dr. Mario Berríos C.* \\ Mg. Zenobio Saldivia M.
}

INTRODUCCIÓN

Estudiar los orígenes de la ciencia en Chile, es entrar en un tema que concita la atención de investigadores interesados en cuestiones epistemológicas, referentes a la génesis y desarrollo de la ciencia en América, como también a estudiosos preocupados de la búsqueda de la identidad latinoamericana. En muchos aspectos tales investigaciones se complementan y se tocan en sus deslindes conceptuales. Ello no es extraño pues analizan el mismo marco cultural, histórico, social y político; en este caso, principalmente el siglo XIX americano.

En este marco cultural e histórico, la noción del conocimiento científico, la visión de la naturaleza y las formas discursivas empleadas para la explicación científica, perfilan la actividad intelectual y social denominada ciencia en dicha época.

En lo que sigue se analiza la visión de la naturaleza en Manuel de Salas (1755-1841) y en Claudio Gay (1800-1973). Ambos autores son relevantes para elucidar la construcción de un concepto de ciencia en Chile, justamente por su preocupación sobre el lugar que ocupan las ciencias naturales y matemáticas.

Aunque las preocupaciones de ambos responden a motivaciones diferentes, el resultado final ha sido poner la piedra angular para comprender la base sobre la cual arrancó la visión de la ciencia actual.

\section{MANUEL DE SALAS O El LUGaR DE la CIENCIA ÚTIL}

Aparentemente el problema de la naturaleza para Salas lo tiene sin cuidado. Lo que le interesa es el uso de la ciencia en forma instrumental, para el posterior dominio de la naturaleza.

La obra de Manuel de Salas ha sido publicada cercana a la celebración de los cien años de vida del Chile independicnte. En efecto, los tres tomos que componen su obra, vieron la luz entre 1910 y 1914. Quien recogió sus aportes y reflexiones fue su descendiente Juan Salas. Don Manuel era todo para todo. «Con el mismo tesón y energía luchaba con los obstáculos que le impedían abrir a la juventud el camino de las profesiones científicas y hacía campaña para que

\footnotetext{
* Departamento de Humanidades, Instituto Profesional de Santiago. Santiago, Chile
} 
sus paisanos adoptaran el culén en lugar del té. como más higiénico y económico.»" Salas fue precursor. Fue testigo de los avances que quiso realizar Carlos III y al mismo tiempo es hombre de la independencia de Chile en 1810. Fue precursor en un doble sentido: preparar a los chilenos para las profesiones científicas y buscar el apoyo en lo nacional.

Su punto de referencia es el mundo de la ilustración. El siglo de las luces reveló las verdades útiles. Escribe: «Estudiando la naturaleza. conociendo las cosas por sus causas y principios se halló la senda única y más corta para hacer felices a los pueblos, dándoles las luces y ocupación cuya falta los abruma.» ${ }^{2}$ En este contexto la naturaleza en sí no interesa en sus especificidades. sino como totalidad útil; "siendo éste y no habiendo otro, el de vulgarizar los conocimientos que facilitan el cultivo de las producciones propias, y que por eso han merecido justamente el nombre de ciencias útiles, lo he procurado constantemente. ${ }^{3}$

Las ciencias están para ser útiles. El estudio de la naturaleza no tiene otro sentido que procurar el cumplimiento de la modernidad anunciada desde la ilustración: «Las ciencias especulativas, necesarísimamente a la conducta del hombre, no pueden ocuparnos a todos, ni servir a todas las necesidades». Así el derecho, la teología, las lenguas clásicas, no solo no sirven para estudiar la naturaleza que nos rodea, sino que además mantiene todo en el statu quo colonial. De lo que se trata es romper este estancamiento ya que de ello emergerá el mundo nuevo que se entreguc. «Una agricultura sin consumos ni reglas, una sombra de industria sin enseñanza ni estímulo, un comercio, o propiamente mercancía de rutina, sin cálculos. combinaciones ni elementos, necesitan para salir de la infancia y tosquedad los auxilios del arte de medir y contar, por ciego defecto no se ve aquí en estas profesiones pasar de la mediocridad como sucede a cada paso en todo el mundo; y por eso la común prosperidad, que nace de la individualidad, no avanza una línea.» ${ }^{4}$

El objetivo, por tanto. es la agricultura, la industria y el comercio. La ciencia es para lograr que la naturaleza sea productiva.

Para Salas existe una relación entre estas ciencias útiles y dominadoras de la naturaleza. con el concepto de hombre ilustrado. El hombre ilustrado es aquel que, salido de la infancia, domina su entorno, y en ese sentido es posible comprender la dura lucha que tuvo que librar para asentar la cátedra de matemáticas en Chile, dado que no existía. Así en 1795 experimenta la necesidad de generar clases de geometría. aritmética y dibujo, porque ellas son necesarias para la agricultura, el comercio y la industria. Solicita salas de clases e insiste en que el gasto para el erario del gobiemo sería poco, y aunque el proyecto es reconocido como laudable, los fondos no alcanzan para ello. Su punto de apoyo es su fïme convicción de que tales estudios son necesarios para superar la mentalidad del escolasticismo, y que la labor de difusión científica que visualiza, trascienda a la sociedad y las costumbres.

El hombre que requiere América es el producto de «las nuevas ciencias y sus auxiliares, aunque encaminadas a determinados objetos. son principios que, abrazando todas las ramas de una educación útil, formará buenos comerciantes, hábiles agricultores y verdaderos mincros;

1. Salas. Manuel de: Escritos de Don Manuel de Salas y documentos relativos a él y su familia. Tomo 1. Imp. Cervantes. Stgo. 1910, p XIII.

2. Ibidem., p. 570.

3. Ibídem., p. 570.

4. Ibidem., p. 571. 
ocupaciones intimamente conexas con el bien del pueblo, de los individuos y del Estado, a que se dedican sin conocimiento o procuran adquirirlos tarde los que emplearon su juventud en estudios que de nada les sirven después. $»^{5}$

El estudio de la ciencia cambia al hombre, lo hace productivo y lo ayuda, ya que ellas son instrumentos del «bienestar de los pueblos, de su riqueza y población.» El camino a que conducen no es meramente pragmático. Es un cambio de mentalidad, es arribar al dominio de la naturaleza: el conocimiento de las ciencias «trae consigo la virtud, valor, poder».

Salas establece una relación causal intrínseca entre:

a) Geometría - aritmética - dibujo.

b) Agricultura - comercio - industria

Ello hace de los ciudadanos:

c) hábiles - buenos - verdaderos, y produce el bienestar del:

pueblo - la riqueza - población.

Por último, tiene que ver con el cambio de la sociedad:

d) virtud - valor - poder.

Las tríadas que ofrece son el camino de la emancipación ilustrada. La síntesis la entrega el mismo Salas: «Esta ha sido toda la política de las naciones que pretenden aventajarnos: honrar las ciencias, particularmente las que mejoran las profesiones lucrativas, convencido de que merece el nombre de sabiduría la que se consagra al bien y consuelo de los hombres.» ${ }^{6}$

El concepto de naturaleza es aquel de la felicidad humana; la naturaleza está envuelta en la ciencia y a su vez ésta. lo que logra es la plenitudi humana. La construcción de esta posibilidad asegura la verdad plena.

En el fondo está la idea de una naturaleza referencial para la ciencia. Y en el centro de este enfoque está la plenitud humana.

\section{LA VISIÓN DE LA NATURALEZA EN CLAUDIO GAY}

La visión de la naturaleza en los estudios de Gay, está comprometida con el modelo teórico recibido de sus maestros europeos. Entre estos Fee. Cuvicr. Juesiéu, Desfontaines y Balbis. ${ }^{7}$

Lo anterior significa que participa de un enfoque expansionista de las ciencias naturales que está en pleno auge. Dicho entoque corresponde a los esquemas explicativos de la ilustración y el positivismo. Se trata de un modelo teórico que pretende extender la aplicación del método científico a una naturaleza que va siendo cada vez más accesible a la aprehensión cognitiva y que va develando todos sus secretos. Entre los autores que consolidan el paradigma explicativo propio de las ciencias de la vida están Lamarck. Laplace. Darwin y' en especial Humboldt. Es un período de desocultamiento de la fysis no europea: un periodo en que lo real golpea con sus particularidades concretas a la inteligencia del viejo continente. Por ello probablemente los taxonomistas, zoólogos. botánicos y otros científicos dedicados al estudio del fenómeno de la vida. tienen los ojos puestos en América puesto que las especies de la flora y la fauráa autóctona no dejan de asombrarlos.

\footnotetext{
5. Ibidem., p. 583 .

6. Ibídem., p. 586 .

7. Cf. Feliú Cruz. G: Clandio Gay. historiador do Chile. Ed. Del Pacifico, Stgo.. 1965. p. 40.
} 
Tal vez por ello el botánico francés -imbuído del mismo asombro de sus pares europeoscancelaba gustoso lo que le pedían los lugareños cn Santiago o Valparaíso, cuando le presentaban por ejemplo algún arácnido, reptil o arbusto desconocidoen principio por él. Y que luego en la soledad de su estudio le reportaba un desafío para sus taxonomías europeas.

Los referentes que concitan el estudio de la naturaleza física de Chile, son para Gay objetos que hay que categorizar, clasificar y asentar dentro del corpus científico europeo. los componentes físicos y biológicods de la naturaleza chilena. son desde luego, partes que integran la totalidad de la realidad física del país, pero son también un desafío para los estudios de las ciencias de la vida.

En Gay, la visión de la naturaleza no está desvinculada de la noción de la ciencia en que se emmarca su labor investigación científica. No puede estarla; más bien la complementa. Si idea del conocimiento científico es equivalente a la obtención de una ordenación sistemática de elementos en que a partir de una operatoria empirica previa, se logra una regla con validez universal. El conocimiento es concebido como una forma de explicitación de los datos del mundo. de acuerdo a leyes que los rigen y que muestran como están encadenados unos objetos con otros. Por ello «quería datos. más datos, sobre todo datos, la mayor cantidad de datos. cuantos datos fuera posible acumular para de un modo racional, experimental, tomando sólo en consideración los hechos reales, escribir la historia física general del mundo... ${ }^{8}$; cn este caso la Historia Física y política de Chile.

La actitud intelectual de recabar los datos del mundo que manifiesta Gay, facilitan la observación y el registro sistemático del entorno físico que tiene que elucidar. Ello es perfectamentc comprensible si tenemos en cuenta que tales datos constituyen el sustrato epistemológico en que descansa su explicación de la realidad.

Los datos sobre las especies y/o eventos propios de nuestro país son los observables de la ciencia natural. En el caso de Gay, era previo informarse de estas porciones biológicas y comprender la dinámica de sus universos específicos, así como apreciar las interacciones entre los mismos, para presentar a continuación la visión del conjunto. Lo anterior significa arribar a la geología. la geografía. la zoología, la botánica, la estadística, la sociología y la historia de la naciente república.

La naturaleza es concebida como un cúmulo de cosascorpóreas y de fenómenos vinculados a los procesos de la vida, con una clara expresión de las peculiaridades tanto de los exponentes orgánicos como inorgánicos, así como de las interacciones de los mismos. Por ello, dar cuenta de los habitats específicos y describir las notas relevantes de los animales, plantas y minerales, es la dirección que asume la ciencia natural en Chile.

El discurso científico de Gay, más allá de su metodología específica, persigue una tarea epistemológica básica: incorporar a la ciencia natural europea un universo biológico desconocido. Se trata por tanto, de presentar los especímenes de una flora y fauna probablemente sospechada en el viejo mundo, pero no conocida. Esta necesidad de conocer el propio cuerpo físico de Chile, es sentida en Gay como una labor previa a un proceso de industrialización del país. Y en lo referente a las comunidades científicas europeas, es percibida como una forma de divulgación de realidades corpóreas existentes en este rincón apartado del mundo.

\footnotetext{
8. Ibídem., p. 44.
} 
Desde el punto de vista cognoscitivo, dicho proceso corresponde a un esfuerzo taxonómico que permite ordenar y unificar la multiplicidad de lo viviente de este universo no explorado. El carácter descriptivo, simplificado y ordenado de esta explicación científica. logra aprehender el vasto mundo abigarrado de formas orgánicas e inorgánicas del cuerpo físico de Chile. Con ello se engarza la naturaleza del país al contex to de la ciencia universal. La tarea aparentemente está lograda.

Sin embargo, una lectura histórica-crítica de la obra de Gay, permite descubrir un recurso metodológico de la presentación discursiva, no suficientemente analizado.

El discurso científico contempla los elementos teóricos y las estructuras proposicionales que describen y dan cuenta de las especies, así como de sus vinculaciones recíprocas. Empero. hay otros elementos cognitivos menos destacados formalmente. que complementan las descripciones: son las reiteradas notas al pié de página; V. gr.:

«3. Kagenekia angustifolia.

K. Foliis lineari-oblongis, acutis, serratis, rigidis, 2. 3. poll. longis, 3. 7 lin. latis; floribus corymbosius. K. Angustifolia. Don., in Ed. Ph. journ. 1832-K. linearifolia. Gay in lit. Vulgarmente Olivillo.

«Este arbolito, que tiene alguna semejanza con el sauce. es muy lampiño. muy frondoso, de siete á diez piés de alto y cargado de muchísimas hojas linear-oblongas, muy angostas, de dos á tres pulgadas de largo, tres o cuatro líneas de ancho, grisáceas, tiesas, lustrosas, dentadas, puntiagudas, muy nerviosas en ambas caras, de color verdega y atenuadas en un peciolo cortísimo...

«El olivillo se cría en los valles de las cordilleras y á lo menos a 4,000 piés de altura.

Florece por los meses de Enero y Febrero, y no muy frecuentemente, según dicen los campesinos. $)^{9}$

¿Es esto una estrategia metodológica para unir el conocimiento vernáculo y el conocimiento de la ciencia natural sobre el cuerpo físico de Chile?, o, ¿es un simple reconocimiento al saber socialmente acumulado de la propia fysis de los chilenos?

Frente a lo anterior nuestra hipótesis puede sintetizarse en los siguientes términos: el nivel de desarrollo de la ciencia europea no agotaba conceptualmente todo lo que era factible explicitar sobre animales y plantas de este rincón del mundo. Desde esta perspectiva se comprende que para Gay era necesario alguna forma de acercamiento al conocimiento regional o local sobre la naturaleza. Pero como este último no era posible insertarlo en el corpus teórico de la ciencia natural europea, por el riesgo de alejarse de las categorías del paradigma imperante, urgía otra solución: las notas descriptivas populares.

Las notas en cuestión, no son un saludo amistoso de Gay a los campesinos y lugareños de la joven república de Chile; son una forma cognitiva complementaria y necesaria para dar cuenta más plenamente de la imagen del Chile físico. Dicho recurso es aceptado como mecanismo explicativo ad-hoc y complementario, pero en el bien entendido que no desafía la estructura explicativa del corpus científico europeo.

Por ello, la visión de Chile que ofrece Gay no es sólo el resultado de su inteligibilidad sumado a los logros de la ciencia europea; es más bien una construcción colectiva: el ingenio

9. Gay, Claudio: «La flora Chilena», Historia Fisica y Política de Chile. T. Il. París, Imp. F. y Thunol. 1847 p. 272 ., p. 586. 
de Gay. la metodología propia de la ciencia natural europea. y esos chispazos pequeños que consignan la explicación popular. Este es el contexto discursivo con que se presenta la naturaleza de la joven república de Chile.

\section{CONCLUSIÓN}

A la base del concepto decimonónico de ciencia en Chile. hay una conceptualización de la naturaleza primero como dominable (Salas), luego como específica (Gay).

Ambas visiones se cruzan posteriormente en la historia del concepto de ciencia en Chile. El positivismo encontró un terreno abonado que permitió una dominación.

Lo que al principio fue una comprensión sucesiva se transforma posteriormente en elementos polares incluso contrapuestos: la ciencia útil y la especificidad de la naturaleza. Sobre la base de esta conceptualización se construye el Chile republicano. 